\title{
Helping the Climate Because Others Do: An Exploratory Analysis of the Psychological Predictors of Intention to Perform High Impact \\ Pro-Environmental Behaviors
}

\author{
Erik Thulin ${ }^{1 *}$ and Abdurakhim Rakhimov ${ }^{2}$ \\ ${ }^{I}$ Center for Behavior and the Environment, Rare \\ ${ }^{2}$ University of Pennsylvania
}

\begin{abstract}
Individual behaviors are major contributors to climate change, and changing those behaviors can have a major effect on the magnitude of the climate crisis. To best design interventions to change these behaviors, and target those most likely to change, we must understand the psychological motivations for engaging in them. Previous work has identified environmental beliefs, political orientation, and social expectations as having significant effects on performing pro-environmental behaviors (PEBs). However, this work has tended to focus on lower impact, commonly performed behaviors. In this exploratory study, we evaluate the relevance of these three constructs on predicting individuals' intention to perform four behaviors previously identified as some of the highest impact individual actions to mitigate greenhouse gas production: driving an electric vehicle, purchasing carbon offsets, switching to a green energy provider, and installing solar panels. Of those three constructs, we find that only social expectations is a strong consistent predictor of intending to perform these high-impact PEBs. These findings suggest that highlighting others performing these behaviors, rather than framing actions in appeals to climate beliefs or targeting those on the political left, may be a particularly effective intervention strategy to drive individual action to mitigate climate change.
\end{abstract}

*Corresponding author: ethulin@rare.org

Version 9/6/2019 
Introduction

Recent climate models project that, unless significant action is taken to stem climate change, our environment and way of life will be seriously challenged by crop failure, extreme weather, and heat-driven mortality (IPCC, 2018). Fully addressing climate change will require comprehensive policy action at both the national and international levels of governance. However, while the fate of such broad policies are uncertain, immediate behavior change is necessary to mitigate the most extreme consequences of our current trajectory (Vandenbergh et al., 2010).

Developing programs to promote pro-environmental behaviors (PEBs) without relying on incentive-based regulation requires an understanding of the psychological motivations capable of driving such behaviors. It is also critical to understand what characteristics make people most amenable to an intervention for efficient segmentation and targeting. Thankfully, a robust cross-discipline literature has developed identifying a variety of candidate motivations.

One consistent nominee for psychological influence is knowledge of the environmental problem. Some findings concern knowledge specific to the narrow problem, where believing that the particular behavior is good for the environment predicts intention to engage in it (Echegaray and Hansstein, 2017). However, other research has shown that more domain general knowledge about environmental problems also predicts pro-environmental behaviors, such as believing that environmental problems are as severe as portrayed by climate scientists predicts contracting from a green energy provider (Welsch and Kuhling, 2009). These findings extend to climate action broadly, where climate change knowledge, and in particular recognizing that it is happening, predicts domain general intention to take action to stop global warming (Heath and Gifford, 2006; Broomell et al., 2015).

Other work has focused on psychographic predictors of PEBs, with a common finding in the United States being the relevance of political orientation. This line of research has shown that conservatives report engaging in PEBs less frequently, even after adjustments are made for various demographics (Coffey and Joseph, 2013). In fact, it seems that conservatives may have an aversion to behaviors being pro-environmental, becoming less likely to choose green products when labeled with an environmental message (Gromet et al., 2013). These effects extend beyond individual focused behaviors, with conservatives having less favorable views of, and being less involved in, environmental movements (Dunlap et al., 2001), as well as becoming less supportive of climate policies when their conservative political identity is made salient (Unsworth and Fielding, 2014).

Finally, social expectations, believing that others are engaging in a behavior and that others believe you should as well, have also been found relevant to environmental behaviors (for 
review, see Farrow et al., 2017). By changing these expectations, researchers have driven changes in a variety of PEBs, such as energy conservation (Allcott, 2011; Schultz et al., 2007), water use (Ferraro, Miranda, \& Price 2011), littering (Cialdini et al., 1990), and reducing food waste (Nomura et al., 2011). These findings are supported by a robust theoretical literature which predicts that concern for these social expectations is expected to be strongest when the behavior is pro-social in nature, such as with PEBs (Bicchieri, 2006; Rand et al., 2014).

While the literature on psychological determinants of PEBs is expansive, it tends to focus on behaviors which are prevalent and relatively easy, such as recycling. However, recent research has shown that these common behaviors have marginal climate impact (Hawken, 2017; Dietz et al, 2009). Instead, the behaviors which are both tractable for individual level intervention while having the greatest effect on greenhouse gasses are surprisingly rare, including the purchasing of carbon offsets, driving an electric vehicle, and switching to green energy, either through contracting through a different provider or installing rooftop solar. Modeling suggests that the adoption of these behaviors by $10 \%$ of Americans would reduce the gap between the expected United States greenhouse gas emissions and the Paris Agreement target by $71 \%$ (Rare and California Environmental Associates, 2019).

Given the impact of adopting these behaviors, understanding the motivations and segmentation specific to those behaviors is critical for the development of high impact behavior change programming for climate change. Due to the differences between these behaviors and those most commonly studied, we developed an exploratory survey to test the degree to which people's intention to perform each of these behaviors was associated with the three key predictors identified in previous literature: climate beliefs, political orientation, and social expectations.

Methods

\section{Respondents}

1488 US respondents were recruited from the Prolific.ac platform to a survey labelled "Behaviors and attitudes study" and were paid 4USD for their participation. This sample was designed to be representative of the U.S. Census adults on age, gender, and ethnicity. Two participants were removed from analysis for failure to provide their gender, resulting in analyzed sample size of $1486.98 .6 \%$ of respondents passed an attention check embedded in the survey. To further ensure representativeness, all analyses were conducted with the sample weighted to be representative to the U.S. Census Bureau's 2018 Current Population Survey (U.S Census, 2019).

\section{Procedure and measures}

The items analyzed were included in a survey administered on the Qualtrics platform, taking the median participant 19 minutes to complete. 
For each of the target behaviors (purchasing an electric vehicle, purchasing carbon offsets, contracting for green energy, and installing solar panels), participants responded to measures of intention to engage in the target behavior, belief that others are engaging in the target behavior, belief that people should engage in the target behavior, and belief that others think that people should engage in the target behavior.

- Intention to perform behavior: For purchasing carbon offsets, contracting for green energy, and installing solar panels, we asked participants "How likely is it that you will [engage in behavior] in the next 12 months?", which they responded to on a 100pt sliding scale labeled "\% chance I will [engage in behavior] in the next 12 months". Due to the infrequency of purchasing a car, intention to purchase an electric vehicle was measured through the item "How likely is it that the next car you purchase is a fully electric car?" on the same 100 pt scale.

- Belief that others are engaging in behavior: For each of the 4 behaviors, we asked participants to imagine ten people they know, and to guess how many of them engage in the target behavior. For example, to assess belief that people are driving electric vehicles, we asked participants to "imagine 10 drivers you know. If you had to guess, how many of them do you think drive a fully electric car?"

- Belief that others should engage in behavior: For each behavior, we asked participants whether they "think that people should [engage in behavior], because it is the right thing to do?". We included the qualifying "because it is the right thing to do" to distinguish non-prudential from prudential reasons for engaging in the behavior.

- Belief that others think people should engage in behavior: Similarly to measuring the belief that others are engaging in the target behavior, we asked respondents to "imagine 10 people you know. If you had to guess, how many of them think that people should [engage in behavior], because it is the right thing to do?"

In addition to these behavior specific items, we measured beliefs about climate change (that it is occuring, that it is caused by humans, and that it has negative consequences) as well as the political orientation of the respondent.

- Climate change beliefs: We adapted scales from the Beliefs about Global Climate Change measure (Heath and Gifford, 2006). This included four items measuring belief that global climate change is occuring (ex. "It seems to me that temperature is warmer now than in years before"), four items measuring the belief that global climate change is caused by human activity (ex. "Global warming is merely a natural fluctuation, not caused by human activity", reverse coded), as well as four items measuring the belief that the consequences of global climate change are negative and significant (ex. "Global 
warming will bring about some serious negative consequences"). We used principal component analysis to reduce these three dimensions into a single climate change beliefs variable.

- Political orientation: We incorporated the measure of political orientation used by the World Values Survey (Inglehart et al., 2014): "In political matters, people talk of 'the left' and 'the right.' How would you place your views on this scale, generally speaking?", adapted to a 100pt slider response scale, with the 0 and 100 points labelled "Left" and "Right" respectively.

Beyond these intentions and beliefs, we also assessed a series of demographic characteristics, including age, gender, race, ethnicity, income, household size, and whether their zip code was in an urban area. Full item text is available in supplemental materials.

Results

To gauge the general momentum behind each high impact PEBs, we first evaluated the distribution of intentions to perform each behavior (Figure 1). ${ }^{1}$

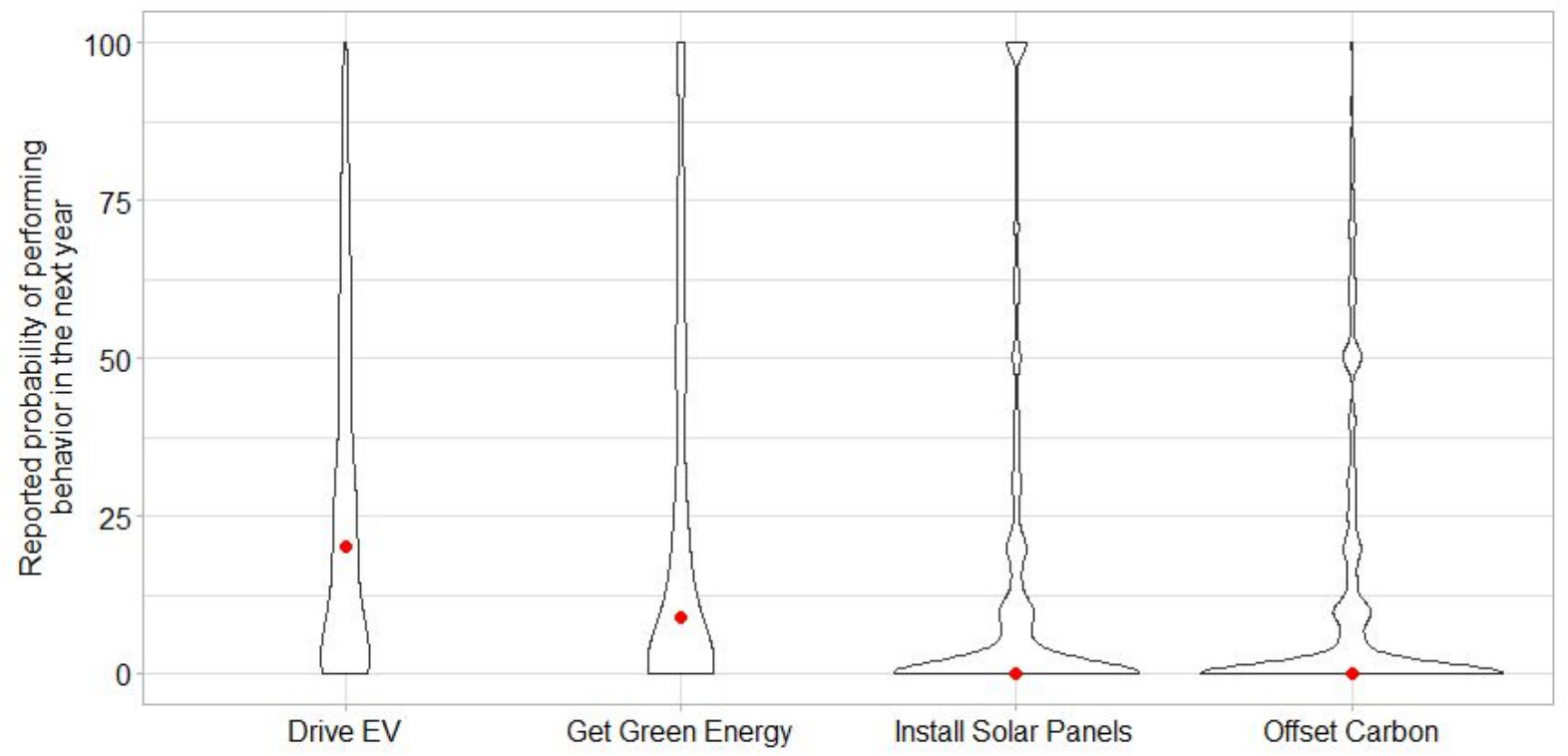

Figure 1. Density plot of the distribution of reported probabilities of engaging in each high-impact environmental behavior in the next year. Red dot represents median response.

We find that across PEBs, most people believe it is very unlikely they will perform the behavior, with the median response for both purchasing carbon offsets and purchasing solar panels at zero

\footnotetext{
${ }^{1}$ Those respondents who report currently owning solar panels or contracting for green energy were coded as having a $100 \%$ chance of doing so in the future.
} 
percent chance. While people believe they are more likely to contract for green energy or purchase an electric vehicle, the large majority of respondents still believe that they are unlikely to do so.

In order to assess the unique contribution of each of the candidate psychological predictors (climate beliefs, political orientation, and social expectations), we constructed linear models regressing intention to perform each of the four behaviors on these predictors. To minimize demographic confounding, we also adjusted for age, gender, race, ethnicity, income, household size, and rural/urban designation. ${ }^{2}$

We standardized all variables in our analysis to a mean of zero and a standard deviation of one to allow for the relative comparison of coefficients in terms of a standard deviation increase of the predictor on a standard deviation increase in intention to perform each of the behaviors. Figure 2 plots the coefficients for each of these models.

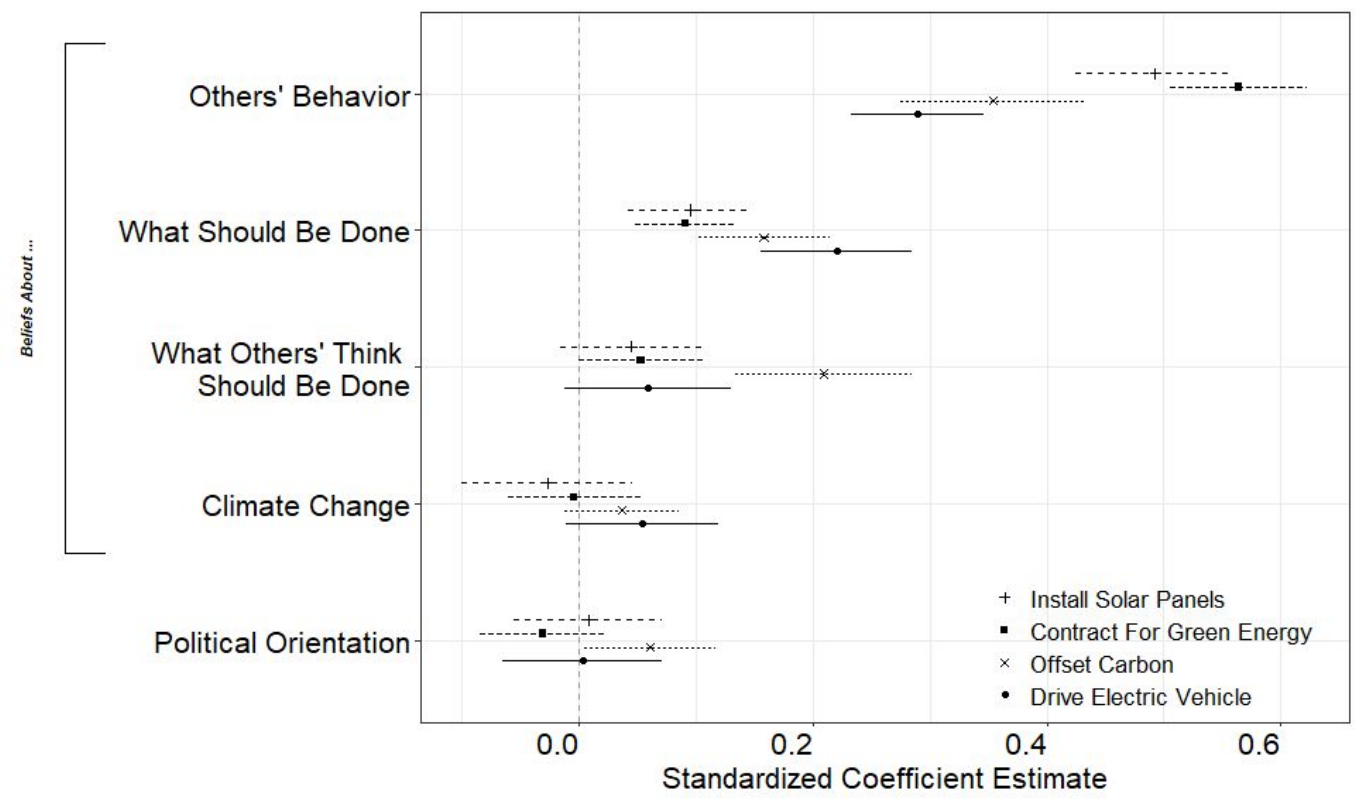

Figure 2. Plots of regression coefficients from linear models regressing intention to perform each behavior on each of the listed covariates, adjusted for demographic controls for age, gender, race, ethnicity, income, household size, and urban/rural designation. All variables are standardized to a mean of zero and a standard deviation of one.

Here we see that, across all four behaviors, the greatest unique predictor of intention to perform high impact PEBs is the respondent's belief that other people are also engaging in the behavior. This is in particular contrast to climate beliefs and political orientation, which show inconsistent and largely insignificant effects.

${ }^{2}$ Respondents who did not intend to buy any vehicle in the next 10 years $(n=121)$ were removed from the analysis of intention to purchase an electric vehicle. 
To assess the degree to which the small size of the coefficients observed for climate beliefs and political orientation are due to the adjustment for social and normative beliefs, we compared each model to an otherwise identical model but with the social and normative beliefs removed as predictors (Table 1). Regression tables with unstandardized coefficients are available in supplemental materials.

Table 1: Regression Results

\begin{tabular}{|c|c|c|c|c|c|c|c|c|}
\hline & \multicolumn{8}{|c|}{ DV: Intention to Perform the Behavior } \\
\hline & \multicolumn{3}{|c|}{ Drive EV } & \multicolumn{2}{|c|}{ Offset Carbon } & \multicolumn{2}{|l|}{ Get Green Energy } & \multirow[t]{2}{*}{ Install Solar Panels } \\
\hline $\begin{array}{l}\text { Beliefs About... } \\
\text { Others' Behavior }\end{array}$ & $\begin{array}{c}0.290^{* * *} * \\
(0.029)\end{array}$ & & $\begin{array}{c}0.354^{* * *} \\
(0.040)\end{array}$ & & $\begin{array}{c}0.565^{* * *} \\
(0.030)\end{array}$ & & $\begin{array}{c}0.493^{* * *} \\
(0.035)\end{array}$ & \\
\hline What Should Be Done & $\begin{array}{c}0.221 * * * \\
(0.033)\end{array}$ & & $\begin{array}{c}0.158^{* * * *} \\
(0.029)\end{array}$ & & $\begin{array}{c}0.091 * * * \\
(0.022)\end{array}$ & & $\begin{array}{c}0.095 * * * \\
(0.027)\end{array}$ & \\
\hline $\begin{array}{l}\text { What Others' Think } \\
\text { Should Be Done }\end{array}$ & $\begin{array}{c}0.059 \\
(0.036)\end{array}$ & & $\begin{array}{c}0.209^{* * *} \\
(0.038)\end{array}$ & & $\begin{array}{l}0.053^{*} \\
(0.027)\end{array}$ & & $\begin{array}{l}0.045 \\
(0.031)\end{array}$ & \\
\hline Climate Change Beliefs & $\begin{array}{c}0.054 \\
(0.033)\end{array}$ & $\begin{array}{c}0.158^{* * * *} \\
(0.035)\end{array}$ & $\begin{array}{c}0.037 \\
(0.025)\end{array}$ & $\begin{array}{c}0.152^{* * *} \\
(0.032)\end{array}$ & $\begin{array}{l}-0.004 \\
(0.029)\end{array}$ & $\begin{array}{l}0.045 \\
(0.037)\end{array}$ & $\begin{array}{l}-0.027 \\
(0.037)\end{array}$ & $\begin{array}{l}0.028 \\
(0.040)\end{array}$ \\
\hline Political Orientation & $\begin{array}{l}0.003 \\
(0.035)\end{array}$ & $\begin{array}{c}0.015 \\
(0.038)\end{array}$ & $\begin{array}{c}0.061 * * \\
(0.029)\end{array}$ & $\begin{array}{c}0.112^{* * *} \\
(0.037)\end{array}$ & $\begin{array}{l}-0.031 \\
(0.027)\end{array}$ & $\begin{array}{l}-0.052 \\
(0.038)\end{array}$ & $\begin{array}{l}0.008 \\
(0.032)\end{array}$ & $\begin{array}{l}0.058 \\
(0.039)\end{array}$ \\
\hline Observations & 1,365 & 1,365 & 1,365 & 1,365 & 1,365 & 1,365 & 1,365 & 1,365 \\
\hline Adjusted $\mathrm{R}^{2}$ & 0.210 & 0.056 & 0.341 & 0.054 & 0.386 & 0.042 & 0.284 & 0.021 \\
\hline
\end{tabular}

Here we find that the coefficients for climate beliefs tend to be reduced substantially with the inclusion of the social and normative beliefs, suggesting that much of the predictive value of climate beliefs may in fact be due to their correlation with these other variables.

\section{Discussion}

Understanding what psychologically motivates engaging in pro-environmental behaviors is critical for designing effective behavioral change interventions to reduce individual contribution to climate change. Previous literature has identified both climate beliefs and political orientation as strong unique predictors of performing or intending to perform such PEBs (ex. Coffey and Joseph, 2013; Heath and Gifford, 2006). Our finding that those variables were poor predictors, is inconsistent with those results. One possible reconciliation is that previous studies tended to focus on higher prevalence, lower impact PEBs such as household recycling. Past public messaging, such as the Ad Council and Keep America Beautiful "I Want to Be Recycled" campaign has closely connected such behaviors to environmental outcomes (I Want to be Recycled, 2019), which may have cognitively associated climate beliefs with the performing of these PEBs. As climate beliefs and action is itself associated with left leaning politics (Dunlap et al., 2001), these campaigns may have in turn also politicized their target PEBs. With regard to previous cross-sectional studies of the association between climate beliefs and PEBs, our work shows that these beliefs are substantially confounded with believing that others are engaging in PEBs, and that after adjusting for believing others are engaging in the behavior, the effect of 
climate beliefs is substantially diminished. Instead, we find support for the notion that believing that others are engaging in a high impact PEB is associated with intention to do so in the future. This finding is consistent with theoretical models of pro-social behavior (Bicchieri, 2006, Rand et al., 2014), as well as empirical results both within the environmental space (Farrow et al., 2017) and in other sectors (Borsari and Carey, 2003; Sheeran et al., 2016; Burchell et al., 2012).

Taken together, these findings have substantial implications for behavioral intervention strategies to drive these high impact PEBs. A lack of association between intention to perform these behaviors and climate beliefs or political orientation suggests that messaging in these terms may not only be minimally effective, as these behaviors are not associated with either, but also that it may be counter-productive, as it may limit the audience to only those who hold the relevant beliefs and orientation. Instead, interventions which increase the belief that others are engaging in the behavior are more likely to be effective. Such interventions have been remarkably successful in increasing pro-social behaviors, ranging across hand-washing (Lapinski et al., 2013; Contzen and Mosler, 2013), political action (Hassell and Wyler, 2019), and curbing college binge drinking (Ridout and Campbell, 2014; Rimal, 2008). These strategies have also been demonstrated to be effective for other PEBs, such as towel reuse (Schultz et al., 2008, Goldstein et al., 2008, Reese et al., 2014), respecting natural environments (Cialdini et al., 2006), sustainable transportation (Kormos et al., 2015), energy efficiency (Allcott, 2011), and water use reduction (Fielding et al., 2013, Richetin et al., 2016). The low prevalence of the studied behaviors does make them a particularly difficult target for this intervention strategy, as raising the saliency of how rarely these behaviors are practiced can lead to a boomerang effect, where people become less likely to practice them (Cialdini et al., 1991; Ayres et al., 2013). To combat this, a growing body of literature has found that focusing on the change over time of the prevalence of the behavior, rather than the prevalence itself, has been effective in low-prevalence contexts (Sparkman \& Walton, 2017; Tankard \& Paluck, 2017; Loschelder et al., 2019). Another strategy for promoting behaviors when the prevalence is low but the size of the population is large would be to describe the number of conformers rather than the prevalence rate (saying, for example, that over 200,000 EVs were registered in 2019, rather than 4\% of 2019 registrations were EVs). This exploits the denominator neglect effect to increase the perceived rate of compliance due to people's inattention to the size of the relevant population (Denes-Raj et al., 1995).

The design of this study results in a number of limitations for its interpretation. While we adjust for possible demographic confounders, the cross-sectional nature of this design means that any causal interpretation of the associations must be caveated. In addition, this study evaluates self reported intention. While using expressed intention, rather than past behavior, makes the direction of causality more plausible for a cross-sectional design, it is possible for future behavior to diverge significantly from those intentions. Finally, as we did not hypothesize a 
particular pattern of predictors, these results need to be interpreted as exploratory rather than confirmatory. This concern is somewhat assuaged by observing the same pattern of results across all four behaviors, suggesting a degree of cross-domain replicability. Future work may extend these findings to address these limitations. In particular, experimental studies can evaluate the degree to which manipulating these types of beliefs results in changing these high impact behavioral outcomes.

References

Allcott, H. (2011). Social norms and energy conservation. Journal of Public Economics, 95(9-10), 1082-1095.

Ayres, I., Raseman, S., \& Shih, A. (2013). Evidence from two large field experiments that peer comparison feedback can reduce residential energy usage. The Journal of Law, Economics, and Organization, 29(5), 992-1022.

Bicchieri, C. (2006). The Grammar of Society: The Nature and Dynamics of Social Norms. New York: Cambridge University Press.

Borsari, B., \& Carey, K. B. (2003). Descriptive and injunctive norms in college drinking: a meta-analytic integration. Journal of Studies on Alcohol and Drugs, 64(3), 331-341.

Broomell, S. B., Budescu, D. V. \& Por, H.-H. (2015). Personal experience with climate change predicts intentions to act. Global Environmental Change, 32, 67-73.

Burchell, K. \& Rettie, R. \& Patel, K. (2012). Marketing social norms: Social marketing and the 'social norm approach'. Journal of Consumer Behaviour, 12(1), 1-9.

Cialdini, R. B., Demaine, L. J., Sagarin, B. J., Barrett, D. W., Rhoads, K., \& Winter, P. L. (2006). Managing social norms for persuasive impact. Social Influence, 1(1), 3-15.

Cialdini, R. B., Kallgren, C. A., \& Reno, R. R. (1991). A focus theory of normative conduct: A theoretical refinement and reevaluation of the role of norms in human behavior. Advances in Experimental Social Psychology, 24, 201-234.

Cialdini, R. B., Reno, R. R., \& Kallgren, C. A. (1990). A focus theory of normative conduct: recycling the concept of norms to reduce littering in public places. Journal of Personality and Social Psychology, 58(6), 1015-1026.

Coffey, D. J. \& Joseph, P. H. (2013). A Polarized Environment: The Effect of Partisanship and Ideological Values on Individual Recycling and Conservation Behavior. American Behavioral Scientist, 57(1), 116-139.

Contzen, N. \& Mosler, H.-J. (2013). Impact of different promotional channels on handwashing behaviour in an emergency context: Haiti post-earthquake public health promotions and cholera response. Journal of Public Health, 21(6), 559-573.

Denes-Raj, V., Epstein, S., \& Cole, J. (1995). The generality of the ratio-bias phenomenon. Personality and Social Psychology Bulletin, 21(10), 1083-1092. 
Dietz, T., Gardner, G. T., Gilligan, J., Stern, P. C., \& Vandenbergh, M. P. (2009). Household actions can provide a behavioral wedge to rapidly reduce US carbon emissions. Proceedings of the National Academy of Sciences, 106(44), 18452-18456.

Dunlap, R. E., Xiao, C. \& McCright, A. M. (2001). Politics and Environment in America: Partisan and Ideological Cleavages in Public Support for Environmentalism. Environmental Politics, 10(4), 23-48.

Echegaray, F. \& Hansstein, F. V. (2017). Assessing the intention-behavior gap in electronic waste recycling: the case of Brazil. Journal of Cleaner Production, 142, 180-190.

Farrow, K., Grolleau, G., \& Ibanez, L. (2017). Social norms and pro-environmental behavior: a review of the evidence. Ecological Economics, 140(C), 1-13.

Ferraro, P. J., Miranda, J. J., \& Price, M. K. (2011). The persistence of treatment effects with norm-based policy instruments: evidence from a randomized environmental policy experiment. American Economic Review, 101(3), 318-22.

Fielding, K. S., Russell, S., Spinks, A. \& Mankad, A. (2012). Determinants of household water conservation: The role of demographic, infrastructure, behavior, and psychosocial variables. Water Resources Research, 48(10).

Fielding, K. S., Spinks, A., Russell, S., McCrea, R., Stewart, R., \& Gardner, J. (2013). An experimental test of voluntary strategies to promote urban water demand management. Journal of Environmental Management, 114, 343-351.

Goldstein, N. J., Cialdini, R. B., \& Griskevicius, V. (2008). A room with a viewpoint: Using social norms to motivate environmental conservation in hotels. Journal of Consumer Research, 35(3), 472-482.

Gromet, D. M., Kunreuther, H. \& Larrick, R. P. (2013). Political ideology affects energy-efficiency attitudes and choices. Proceedings of the National Academy of Sciences, $110(23)$, 9314-9319.

Hassell, H. J. G. \& Wyler, E. E. (2019). Negative Descriptive Social Norms and Political Action: People Aren't Acting, So You Should. Political Behavior, 41(1), 231-256.

Hawken, P. (2017). Drawdown: The most comprehensive plan ever proposed to reverse global warming. New York: Penguin Books.

Heath, Y. \& Gifford, R. (2006). Free-Market Ideology and Environmental Degradation: The Case of Belief in Global Climate Change. Environment and Behavior, 38(1), 48-71.

Inglehart, R., C. Haerpfer, A. Moreno, C. Welzel, K. Kizilova, J. Diez-Medrano, M. Lagos, P. Norris, E. Ponarin \& B. Puranen et al. (eds.). (2014). World Values Survey: Round Six Country-Pooled Datafile 2010-2014. Madrid: JD Systems Institute.

IPCC. (2018) Global warming of $1.5^{\circ} \mathrm{C}$. An IPCC Special Report on the impacts of global warming of $1.5^{\circ} \mathrm{C}$ above pre-industrial levels and related global greenhouse gas emission pathways, in the context of strengthening the global response to the threat of climate change, sustainable development, and efforts to eradicate poverty.

I Want to be Recycled (2019). About the Campaign. I Want to be Recycled. 
Kraft-Todd, Yoeli, E., Bhanot, S. \& Rand, D. (2015). Promoting cooperation in the field. Current Opinion in Behavioral Sciences, 3(0), 96-101.

Kormos, C., Gifford, R., \& Brown, E. (2015). The Influence of Descriptive Social Norm Information on Sustainable Transportation Behavior: A Field Experiment. Environment and Behavior, 47(5), 479-501.

Lapinski, M. K., Maloney, E. K., Braz, M. \& Shulman, H. C. (2013). Testing the Effects of Social Norms and Behavioral Privacy on Hand Washing: A Field Experiment. Human Communication Research, 39, 21-46.

Loschelder, D., Siepelmeyer, H., Fischer, D. \& Rubel, J. (2019). Dynamic Norms Drive Sustainable Consumption: Norm-based Nudging Helps Café Customers to Avoid Disposable To-Go-Cups. Journal of Economic Psychology, 10.

Nomura, H., John, P. C., \& Cotterill, S. (2011). The use of feedback to enhance environmental outcomes: A randomised controlled trial of a food waste scheme. Local Environment, 16(7), 637-653.

Rand, D. G., Yoeli, E., \& Hoffman, M. (2014). Harnessing reciprocity to promote cooperation and the provisioning of public goods. Policy Insights from the Behavioral and Brain Sciences, 1(1), 263-269.

Rare and California Environmental Associates. (2019). Changing Behaviors to Reduce U.S. Emissions: Seven Pathways to Achieve Climate Impact. Arlington, VA: Rare.

Reese, G., Loew, K. \& Steffgen, G. (2014). A Towel Less: Social Norms Enhance Pro-Environmental Behavior in Hotels. The Journal of Social Psychology, 154(2), 97-100.

Richetin, J., Perugini, M., Mondini, D., \& Hurling, R. (2016). Conserving water while washing hands: The immediate and durable impacts of descriptive norms. Environment and Behavior, 48(2), 343-364.

Ridout B. \& Campbell, A. (2014). Using Facebook to deliver a social norm intervention to reduce problem drinking at university. Drug and Alcohol Review, 33(6), 667-673.

Rimal, R. (2008). Modeling the relationship between descriptive norms and behaviors: A test and extension of the theory of normative social behavior (TNSB). Health Communication, 23, $103-116$.

Schultz, P., M. Khazian, A. \& Zaleski, A. (2008). Using Normative Social Influence to Promote Conservation Among Hotel Guests. Social Influence, 3(1), 4-23.

Schultz, P. W., Nolan, J. M., Cialdini, R. B., Goldstein, N. J., \& Griskevicius, V. (2007). The constructive, destructive, and reconstructive power of social norms. Psychological Science, 18(5), 429-434.

Sheeran, P., Maki, A., Montanaro, E., Avishai-Yitshak, A., Bryan, A., Klein, W., Miles, E., \& Rothman, A.J. (2016). The impact of changing attitudes, norms, and self-efficacy on health-related intentions and behavior: a meta-analysis. Health Psychology, 35(11), $1178-1188$. 
Sparkman, G., \& Walton, G. M. (2017). Dynamic Norms Promote Sustainable Behavior, Even if It Is Counternormative. Psychological Science, 28(11), 1663-1674.

Tankard, M. E. \& Paluck, E. L. (2017). The Effect of a Supreme Court Decision Regarding Gay Marriage on Social Norms and Personal Attitudes. Psychological Science, 28(9), 1334-1344.

Unsworth, K. L. \& Fielding, K. S. (2014). It's political: How the salience of one's political identity changes climate change beliefs and policy support. Global Environmental Change, 27, 131-137.

U.S. Census Bureau. Current Population Survey (2019), 2018 ASEC. Washington, D.C.: U.S. Department of Labor, Bureau of the Census.

Vandenbergh, M. P., Stern, P. C., Gardner, G. T., Dietz, T., \& Gilligan, J. M. (2010). Implementing the behavioral wedge: Designing and adopting effective carbon emissions reduction programs. Environmental Law Reporter (ELR), 40, 10547.

Welsch, H. \& Kühling, J. (2009). Determinants of pro-environmental consumption: The role of reference groups and routine behavior. Ecological Economics, 69(1), 166-176.

Ziegler, A. (2017). Political orientation, environmental values, and climate change beliefs and attitudes: An empirical cross country analysis. Energy Economics, 63(C), 144-153. 